\title{
Criterios de Sujeción de las Rentas del Teletrabajo Internacional. Residencia Fiscal y Doble Imposición Internacional
}

\section{RESUMEN}

Juan Jesuis Martos

Universidad de Granada

\begin{abstract}
Los sistemas fiscales se basan en el Principio de Soberania Fiscal. Fn base a este. establecen figuras tributarias con criterios de sujeción personales (residencia), que gravan la renta universal del sujeto (residente), y reales (fuente), que solo gravan la renta generada en su territorio (no residente). Debido a lo anterior y a los diferentes modos de delimitar la residencia fiscal en cada jurisdicción. surgen problemas de doble imposición internacional. Las soluciones que los Ordenamientos prevén son de carácter unilateral (métodos de Exención y métodos de imputación) y bilateral, mediante la firma de Convenios para evitar la doble imposición internacional, donde se establece un mecanismo de cesión de soberania para las partes, que determinara el Estado que, en exclusiva, podrá gravar y recaudar el tributo. En este marco, las rentas internacionales del teletrabajo incorporan la novedad de localizar a trabajador y empresa en jurisdicciones distintas, sin que el empleado tenga que desplazarse hasta el Estado donde se encuentra el centro de trabajo, lo que altera, en determinados supuestos. los criterios de sujeción establecido en los convenios y en la normativa IRNR.
\end{abstract}

Palabras clave: Sistema Fiscal, Residencia Fiscal, Teletrabajo

\section{SUMMARY}

Fiscal systems are based on the Fiscal Principle of Sovereignty. On this basis, they establish tributary figures of personal subjective criteria (residency). which levy universal tax of the subject (resident), and real (source) that levy on the income generated in the territory (non-resident). Due to this and to the different methods of establishing fiscal residency in each jurisdiction. problems of double international taxation arise. The solutions that the "Ordenamientos" foresee are of unilateral character (methods of exemption and methods of imputation) and bilateral. by 
signing agreements to avoid the double international imposition, where a mechanism of cession of sovereignty for the partsis established, which will determine the State that, with full exclusivity; will be able to tax and collect the tribute. In this frame, the international revenues of callcentre jobs incorporate the newness of locating worker and company in different jurisdictions, without the employee needing to move to the State where the business is located. This alters, in certain situations, the criteria of subjections established in the foresaid agreements and in the IRNR legislation.

Key words. Fiscal System, Fiscal Head Office. Telework.

\section{INTRODUCCION}

El carácter definitorio del teletrabajo radica en la posibilidad de prestar un serviciø laboral a distancia, sin necesidad de que el sujeto se desplace al centro de trabajo de la empresa, pudiendo realizar su tarea desde el lugar deseado, enviando el resultado, normalmente, vía electrónica.

Nos encontramos con supuestos típicos de percepción de rentas por parte del trabajador; gravados en la práctica totalidad de los sistemas fiscales, pero con la existencia de una particularidad en las operaciones internacionales. Se puede hacer frecuente una situación francamente inusual hasta la aparición de este fenómeno: Poder residir y trabajar físicamente en un Estado y que el fruto de ese trabajo se destine a una empresa, pagadora del servicio, que resida o se encuentre establecida en otra jurisdicción.

Esta nueva modalidad laboral, libera a un sector importante de trabajadores de la obligación de residir en el lugar donde se encuentre el establecimiento o centro de trabajo: donde sus servicios son requeridos, lo que les otorga mayor libertad para decidir donde fijar su residencia, cuestión que resulta capital para determinar las reacciones previstas ea los sistemas tributarios.

El teletrabajador, a la hora de establecer su residencia habitual, y siendo el factor trabajo ciertamente irrelevante, se basará en vínculos afectivos, familiares, sociales o climáticos parạ: conformar su decisión. Sin embargo, junto a todos estos, no debemos olvidar otra circunstancia que, a medida que las rentas se hacen mas elevadas, se pondera al alza dentro del conjunto de factores decisorios, la carga fiscal soportada por la percepción de la remuneración convenida!. $\mathrm{Y}$ es que los sectores donde cobra pujanza esta nueva actividad están principalmente: relacionados con la informática y los Servicios de la Sociedad de la información ${ }^{2}$.

Todos estos hechos plantean la necesidad de exponer cual es la reacción de nuestro sistema impositivo ante lo que podríamos calificar como teletrabajo internacional, definido como el supuesto en el que trabajador y empresa residen 0

1. Hasta ahora, se habian presentado casos de artistas del espectáculo y deportistas de élite que decidian? transladar su residencia por motivos fiscales. Sin embargo, a diferencia del teletrabajo, estos últimos debíanis desplazarse físicamente hasta el lugar donde prestasen su servicio, lo que podia ser utilizado para atraerat tributación las rentas en esa jurisdicción. Además, también se podian presentar problemas para acreditär lậ nueva residencia fiscal y para desvincularse definitivamente de su residencia anterior.

2. Este concepto aparece a nivel comunitario en la Directiva $98 / 34 / C E$, de 22 de Junio, por la que se establece un procedimiento de información en materia de las normas y reglamentaciones técnicas y de lass 
reglas relativas a los servicios de la Sociedad de la Información, y ha sido reiterada en varias Directivas posteriores, como la Directiva $1998 / 84 / \mathrm{CE}$ de 20 de Noviembre, relativa a la protección jurídica de los servicios de acceso condicional o basados en clicho acceso y en el anexo de definiciones de la Direcriva 2000): 31/CE. de 8 de Junio, relativa a determinados aspectos juridicos de los servicios de la sociedad de la Información. en particular el comercio electrónico en el mercado interior (Directiva sobre el comercio electrónico). El legislador comunitario define los servicios de la sociedad de la información como "cualquier servicio prestado normalmente a título oneroso, a distancia, mediante un equipo electronico para el tratamiento (incluida la comprensión digital) y el almacenamiento de datos. y a petición individual de un receptor de un servicio". Para posteriormente matizar en la Directiva sobre el comercio electrónico que "... Los servicios de la Sociedad de la Información no se limitan cenicamente a servicios que dan lugar a la contratación en linea. sino también, en la medida en que representan una actividad económica, son extensivos a servicios no remunerados por sus destinatarios".

En nuestra normativa interna, se traslada a grandes rasgos esta definición en el an.2.2 del RD $1337.1 \% 99$, de 31 de Julio, por el que se regula la remisión de información en materia de normas y reglamentaciones recnicas y reglamentos relativos a los servicios de la Sociedad de la Información considera servicios de la sociedad de la Información a "... todo servicios prestado normalmente a cambir, de unia remuneración, a distancia. por via electrónica y a petición individual de un destinatario de servicios".

También en el anteproyecto de ley sobre el comercio electronico, tras reiterar la anterior definición, añade que "El concepto de servicio de la Sociedad de la Información comprende también los servicios no remunerados por sus destinatarios, en la medida en que constituyan una actividad económica para el prestador de serricios".

Sin embargo, y pese al inicial caräcter genérico de la definición, tenemos que destacar que la Directiva Europea sobre el comercio electrónico excluye del concepto los sen icios de radiodifusión sonora y televisiva. Junto a éstos, el anteproyecto de ley sobre el comercio electrónico tampoco incluye el servicio del teletexto televisivo y los servicios prestados por medio de telefonia vocal. fax o telex. Entendemos que estas exclusiones se deben a que estos servicios tradicionales tienen su propio marco regulador, y éste és considerades como vilido por el legislador.

Así, pese a que alguno de estos servicios participan plenamente de los caracteres de esta definición, son excluídos cuando son prestados a través de sistemas ajenos a Internet, como señala el anexo del anteproyecto de ley del comercio electrónico para el caso de la televisión a la carta: "No tendran la consideracion de servicios de la Sociedad de la Información...... los servicios de radiodifusión televisiva (incluícos los servicios de cuasivideo a la cara), contemplados en el art.3.a de la Ley $25 / 1994$. de 12 de Julio. por la que se incorpora al Ordenamiento juridico español la Directiva 89/552/CEE, de 3 de octubre....": Sin embargo. cuando el servicio se presta a través de Internet, queda encuadrado dentro de la definición. manifestando el anteproyecto de ley del comercio electrónico que es un servicio de la Sociedad de la Información "El vídeo bajo demanda. como servicio en que el usuario puede seleccionar a través de la red, tanto el programa deseado como el momento de su suministro y recepción, y, en general, la distribución de contenidos previa petición indiviclual".

Junto con el servicio de video bajo demanda prestado on line. el anteproyecto de ley del comercio electrónico considera que "Son servicios de la Sociedad de la Información, entre otras, las siguientes actividades económicas:

La contratación de bienes o servicios por via electrónica.

La organización y gestión de subastas por medios electrónicos o de mercados y centro comerciales virtuales La gestión de compras en la Red por grupos de personas

El envio de comunicaciones comerciales

El suministro de información por vía telemática

El alojamiento de información, aplicaciones o servicios, facilitados por el destinatario del servicio de alojamiento El ofrecimiento de instrumentos de boesqueda, acceso y recopilación de datos, la transmisión de información a traves de una red de telecomunicaciones".

Pese a que la Sociedad de la Información vaya mas allá de Internet, resulta que la calificación legal de los servicios prestados en ésta se circunscribe a aquellos efectuados en el desarrollo de una actividad económica relacionada directamente con la Red. 
se encuentran establecidos en jurisdicciones fiscales distintas, y las consecuencias que prevé ante los posibles cambios internacionales de residencia por parte dèl teletrabajador, en la búsqueda de unas condiciones fiscales más benévolas; especialmente a zonas calificadas reglamentariamente como paraísos fiscales.

Pero para contextualizar correctamente el fenómeno del teletrabajo en el mareo tributario, y de forma previa a las cuestiones anteriormente planteadas, resulta necesario comenzar exponiendo brevemente algunas notas sobre el Principio de Soberanía Fiscal, nuclear en los sistemas tributarios e inherente a todos los Estados, especialmente aquellas manifestaciones que someten a tributación la renta generada por obligación personal o por obligación real de contribuir, y los problemas de doble imposición internacional que se presentan como consecuencia del ejercicio pleno del mismo y de la falta de coordinación de los sistemas fiscales.

El Principio De Soberanía Fiscal. La Complementariedad De La Vinculación Personat $\mathbf{Y}$ Real De Contributr Y los Problemas De Doble Imposición Internacional

\section{El Principio de Soberania fiscal y el vinculo personal y real de sujeción}

El Principio de soberanía fiscal ${ }^{3}$ es entendido como el poder atribuible a cada Estado para someter a imposición aquellos hechos que, teniendo algún vínculo con el mismo, denoten capacidad económica. En su vertiente externa, este Principio no es mas que el reconocimiento explicito a cada jurisdicción para diseñar y regular de forma autónoma su propio sistema fiscal.

Sin embargo, el ejercicio de este Principio, el alcance de la independencia de los Estados para abordar su política tributaria, no resulta ilimitado. Se requiere que exista suficiente conexión entre alguno de los elementos, objetivo o subjetivo, del hecho imponible de cualquier figura tributaria y el Estado en cuestión. No necesitan que en la configuración de la relación jurídico tributaria aparezcan elementos. nacionales, sino que también podrán aparecer otros, subjetivos y/o objetivos, de carácter extranjero, siempre que exista vinculación suficiente con el Estado impositer ${ }^{4}$.

Pero estos dos aspectos, la condición o la naturaleza del sujeto y el hecho objetivo. que realiza, no solo deben ser entendidos como límites del Principio de Soberanía Fiscal, sino también como caracteres que lo dotan de contenido, ya que uno u otro serán los criterios de sujeción de los diferentes tributos que conformen su sistema fiscal.

3. SAINZ DE BUJANDA, Fernando, (1975) "Derecho Fiscal Internacional", Hacienda y Derecho 1; I.E.P.; FERREIRO LAPATZA, José J., (1996) Curso de Derecho Financiero Español, Marcia Pons, Madrid,

4. Los Estados atraen hechos producidos fuera de su territorio, siempre que de algún modo puedain conectarse con este, en lo que la doctrina ha denominado ultraterritorialidad de las normas tributarias. Consuiltese a SOPENA, (1991) "La eficacia de las leyes tributarias en el espacio", Comentarios a la LGT y lineas para sti reforma col.I, Insituto de Estudios Fiscales, Madrid. 
Por tanto, la vinculación de los hechos gravables con el Estado se concreta en estos criterios de sujeción o puntos de conexión previstos en la normativa tributaria, distinguiéndose dos grandes grupos: Personales y reales.

Los puntos de conexión de tipo personal se refieren a sujetos pasivos que detentan una condición que implica una relación directa y estable con el Estaclo, sujeto activo de la relación tributaria, en virtud de la cual, se someten a gravamen por su renta mundial, con independencia del lugar de su obtención ${ }^{5}$. Esa condición personal del contribuyente utilizada por los Estados suele ser la residencia fiscal" o la nacionalidad, si bien es cierto que es el primero el que predomina de forma abrumadora en la mayoría de los sistemas fiscales, teniendo el segundo carácter residual'.

Por el contrario, los puntos de conexión de carácter real someten los hechos a imposición en el lugar de la fuente, en el lugar donde se originan. Focalizan su atención en el hecho, quedando el sujeto que los realiza, residente o no residente, nacional o extranjero, y que se convierte en contribuyente, obligado a responder solo de la capacidad económica manifestada en el mismo, pero no por toda su renta mundial.

Los sistemas fiscales, lejos de considerar antagónicos ambos criterios, los combinan y los utilizan para atraer todas la manifestaciones de riqueza relacionaclas con su jurisdicción, por obligación personal o real. En esta línea, nuestro Ordenamiento impone la obligación personal de contribuir a todos aquellos que sean residentes en territorio

5. GALTÉS VICENTE, Merixxell, (2001) "El concepto de Residencia de las Personas Físicas" Revista Economía Social y de la Empresa, $n^{\circ} 37$, manifiesta que: "El principio de imposición por renta mundial ha sido duramente criticado y es interesante considerar como los diversos estados justifican esta comprensiva forma de imposición. El argumento mas importante usado por la mayoría de los legisladores se basa en el mantenimiento de la estructura de un Estado y los beneficios sociales que de ella se derivan. El deber de contribuir está vinculado a las ventajas que el contribuyente obtiene de su pertenencia a la colectividad. directa o indirectamente. por medio de los bienes o servicios públicos que le permiten el vivir o actuar en un territorio (....) El fundamento de la relación entre el contribuyente y la norma tributaria en un territorio determinado no es otro que el de la pertenencia política, social y económica a un ordenamiento jurídico que sujeta su conducta y grava los resultados que genera, en tanto manifestaciones de capacidad económica, como deber de contribuir al levantamiento del gasto público, por las ventajas y beneficios que le procura la respectiva vida económica colectiva".

6. Junto a la Residencia, como criterio de sujeción personal por excelencia en los sistemas fiscales. se ha generalizado, en la mayor pare de los mismos, el Principio de personalización del establecimiento permanente, en virtud del cual se convierte a éstos en obligados tributarios similares a los residentes. En base a esta equivalencia, las rentas mundiales generadas por un establecimiento permanente no residente se someten a gravamen en la jurisdicción donde se localice el mismo. Para profundizar en el estudio de esta cuestión consúltese a DE JUAN LEDESMA, Alvaro, (1995) "La personalización de los establecimientos permanentes", Revista de Estudios Financieros, $n^{\circ} 146$. Este autor señala que: "la legislación española ha evolucionado desde considerar al establecimiento como un caso de obliación real de contribuir (es decir, incluyendo en su base sólo las rentas obtenidas en el páis de la fuente), a un supuesto de obligación personal (diga lo que diga la literalidad de la norma) integrando en la base todas las rentas, cualquiera que sea su fuente, incluso la proveniente de paises terceros, es decir, gravando el beneficio mundial".

7. El punto de conexión de la nacionalidad es el utilizado por EE.UU., pero el resto de los Estados miembros de la OCDE se inclinan por la utilización del criterio de la Residencia. 
nacional, gravando su renta mundial, a través de dos tributos de aplicación alternativa, dependiendo de la naturaleza personal del perceptor de las rentas: El Impuesto sobre la Renta de las Personas Físicas (IRPF) y el Impuesto sobre: Sociedades. Además, también contempla otra figura tributaria que establece la obligación real de contribuir, el Impuesto sobre la Renta de los No Residentes (IRNR), que grava la renta obtenida en nuestro territorio por los no residentes $y_{i}$ obviamente, no su renta mundial.

\section{Doble imposición internacional y métodos para su eliminación}

La voracidad propia de todos los Estados por ampliar el alcance del Principio de Soberanía fiscal, provoca conflictos impositivos al concurrir, sobre un mismo hecho, distintas jurisdicciones que lo reclaman en base a la vinculación, personal o real, del mismo. Estamos ante lo que se conoce como supuestos de doble o pluri-imposición internacional, dependiendo del número de jurisdicciones, dos o más, respectivamente, que, atendiendo a su propia normativa, se consideren competentes para gravar esa. manifestación de riqueza.

La percepción de rentas internacionales por un sujeto es el hecho tipo que puede provocar estos supuestos, al quedar gravado por obligación personal por su renta mundial en la jurisdicción en la que reside (o su nación, si este es el criterio de vinculación personal seguido en su patria), pero también, si la renta se ha generado en otro Estado, por obligación real de contribuir en este último, como lugar de la fuente.

También son clásicos los supuestos en los que a un sujeto se le puede atribuir obligación personal de contribuir en varias jurisdicciones, al ser considerado como residente, al no existir un concepto idéntico y perfectamente coordinado. de residencia fiscal entre los distintos Estados, lo que provocaría una concurrencia impositiva sobre su renta mundial por todas aquellas que le atribuyesen esta condición ${ }^{8}$.

Estas situaciones de descoordinación entre los sistemas fiscales resultan hartamente desaconsejables, al suponer un serio obstáculo para el desarrollo de las relaciones internacionales y para el flujo transfronterizo de bienes y servicios, por lo que los Estados han articulado medidas tendentes a erradicarlas.

Al margen del fenómeno, relativamente reciente, de armonización fiscal entre: jurisdicciones cercanas en algunas partes del planeta y que una vez alcanzada en grado:

8. Otro supuesto especial que quedaría encuadrado dentro de este grupo es el de aquellos sujetos: que son nacionales de un Estado que utiliza este criterio personalista, pero que residen en otro distinto, que a su vez utiliza un criterio de vinculación personal diferente, la residencia. 
suficiente acabaría con estos problemas", las medidas que suelen ser previstas por los sistemas fiscales son de dos tipos, dependiendo de su carácter interno o internacional"."

\section{a) Medidas unilaterales}

A nivel interno y de forma unilateral, se puede establecer un método de exención para renunciar a gravar una renta cuando ya haya sido gravada en otro Estado.

Una variante de este método es el denominado sistema de exención con progresividad. Consiste en integrar, en primera instancia, la base imponible de la renta gravada en otro Estado, para poder calcular un tipo medio de gravamen en base a la renta global del sujeto. Una vez calculado, éste se aplica a la renta obtenida por el sujet(s, sin incluir en ella aquella que ha sido gravada en otro Estado y que anteriormente se tuvo en cuenta a los solos efectos de la determinación de tipo medio de gravamen ${ }^{11}$.

Otra alternativa se presenta a través del método de imputación o del crédito fiscal, que somete a gravamen esa renta, pero que, posteriormente, cleduce en cuota el tributo pagado por ese mismo hecho en otra jurisdicción'2. Este puede ser utilizado estableciendo un tope máximo para la deducción en cuota del tributo pagado en otra jurisdicción, límite que suele venir marcado por la cuota que hubiese tenido que pagar por esa renta si se hubiese obtenido libre de tributación. Como consecuencia, en esta variante del método de imputación se deduciría de la cuota devengada la menor de las dos cantidades siguientes:

La cuota del impuesto efectivamente pagado en otro país.

El resultado de aplicar el tipo medio efectivo de gravamen (calculado antes de aplicar la deducción del impuesto extranjero) del país de residencia a la parte de la base imponible gravada en el país de la fuente.

9. RUBIO GUERRERO, Juan J., (2001) "Los Principios básicos de la fiscalidad internacional y la doble imposición internacional", Dir. CORDÓN EZQUERRO, Teodoro. Mamual de Fiscalialad miternacional. Instituto de Estudios Fiscales. señala que: "El proceso histórico bajo el que se ha configurado la instrumentación de las soluciones encaminadas a corregir el fenómeno de la doble imposición internacional ha tenido como punto de partida el diseño de medidas internas de caráter unialeteral. En una etapa posterior se ha recurrido a la firma de convenios fiscales bilaterales y a la elaboración de convernios de carácter multiateral, para, en una última fase, acometer intentos de armonización fiscal como requisito previo a la integración económica de los paises de un mismo ábito geográfico y con afinidades económicas significativas". En estas líneas, el autor describe cronológicamente los métodos surgidos para coordinar los sistemas fiscales y evitar los conflictos señalados, pero debemos apostillar que la aparición de los últimos no ha venido a sustituir a los primeros. 'sino que todos conforman el haz de medidas de las que se dotan, unilateral, bilateral o multilateralmente los Estados para corregir este fenómeno.

10. RUBIO GUERRERO, Juan J., (20001) "Los Principios básicos de..." op.cit.

11. Esta variante resulta ser mas respetuosa con la progresividad del impuesto (en caso de que lo fuese). Si se incrementa el tipo impositivo a medida que aumenta el intervalo de renta obtenida, la incorporación de la renta gravada en otro Estado, a los solos efectos de la determinación del tipo medio de gravamen, provocará que este último se eleve respecto del que obtendríamos de aplicar el método de exención simple. En consecuencia, provocaria que se obtuviese una cuota mayor para el contribuyente, por efecto de la progresividad.

12. Con este último método se consigue que el contribuyente solo quede obligado por la parte no pagada previamente, y que se mantenga la progresividad del tributo. 


\section{b) Convenios de doble imposición}

Junto a las medidas internas expuestas, se han popularizado otros mecanismos para resolver estos conflictos: Los Convenios para evitar la Doble Imposición Internacional de Renta y Patrimonio.

Pueden tener carácter multilateral, pero la práctica totalidad de los Convenios firmados tienen naturaleza bilateral, y en ellos se produce una renuncia de soberanía fiscal mutua para coordinar los sistemas fiscales de los Estados contratantes y eliminar la doble imposición internacional. Dependiendo del supuesto planteado, se establecen unas reglas para la atribución en exclusiva, a una de las jurisdicciones en conflicto, de la potestad tributaria, de manera que fuese ésta la única que gravaría el hecho, renunciando el otro Estado a su soberanía fiscal respecto al mismo.

Pese a que han sido varios los Modelos de Convenios que se han planteado en los foros internacionales, es el Modelo Convenio de Doble Imposición de la OCDE el predominante ${ }^{13}$ y el utilizado por España en la práctica totalidad de los acuerdos que ha firmado ${ }^{14 .}$

13. La OCDE publicó su primer Modelo de Convenio en 1963, que fue modificado y actualizado por sucesivas ediciones de 1977 y 1992. A partir de esa fecha el Modelo de Convenio adoptó el formato de hojas intercambiables, con el fin de permitir su actualización permanente.

Como contraposición a este modelo, surgió en primer lugar, el Modelo de Convenio propuesto por los miembros del acuerdo de Cartagena o Pacto Andino y, posteriormente, el Modelo de Convenio de la ONU. que data de 1980 y que ha sido actualmente revisado. Estos surgen con la finalidad de ofrecer un Modelo alternativo a los paises receptores de inversiones o fuente de rentas, ya que el Modelo de la OCDE exige a estos un mayor sacrificio a efectos de su soberania fiscal que a los paises inversores o "ricos". Sin embargo, desde posiciones pragmáticas, tenemos que advertir que el número de Conveniọs firmados internacionalmente que se apartan del propuesto por la OCDE resultan minimos, casi residuales; por lo que debemos estudiar las cuestiones controvertidas objeto de este comentario en relación a aquel.

14. Los Convenios firmados por España para evitar la doble imposición internacional en renta y patrimonio en vigor a 1 de mayo de 2002.

\begin{tabular}{llllll} 
ESTADO & FECHA & ESTADO & FECHA & ESTADO & FECHA \\
\hline Alemania & $08 / 04 / 68$ & Ecuador & $05 / 05 / 93$ & Luxemburgo & $04 / 08 / 87$ \\
Argentina & $09 / 09 / 94$ & Eslovaquia & $14 / 07 / 81$ & Marruecos & $22 / 05 / 85$ \\
Australia & $29 / 12 / 92$ & Estados Unidos & $22 / 12 / 90$ & Méjico & $27 / 10 / 94$ \\
Austria & $06 / 01 / 68$ & Filipinas & $15 / 12 / 94$ & Noruega & $10 / 01 / 01$ \\
Bélgica & $27 / 10 / 72$ & Finlandia & $11 / 12 / 68$ & Polonia & $15 / 06 / 82$ \\
Bolivia & $10 / 12 / 98$ & Francia & $12 / 06 / 97$ & Portugal & $07 / 11 / 95$ \\
Brasil & $31 / 12 / 75$ & Holanda & $16 / 10 / 72$ & Reino Unido & $18 / 11 / 76$ \\
Bulgaria & $12 / 07 / 91$ & Hungria & $24 / 11 / 87$ & Rumania & $02 / 10 / 80$ \\
Canadá & $06 / 02 / 81$ & India & $08 / 02 / 95$ & Federación Rusa & $06 / 07 / 00$ \\
Corea del Sur & $15 / 12 / 94$ & Indonesia & $14 / 01 / 00$ & Suecia & $22 / 01 / 77$ \\
Chequia & $14 / 03 / 81$ & Irlanda & $27 / 12 / 94$ & Suiza & $03 / 03 / 67$ \\
China & $25 / 06 / 92$ & Israel & $01 / 01 / 01$ & Tailandia & $09 / 10 / 98$ \\
Cuba & $10 / 01 / 01$ & Italia & $22 / 12 / 80$ & Túnez & $03 / 03 / 87$ \\
Dinamarca & $28 / 01 / 74$ & Japón & $02 / 12 / 74$ & Estados de la antigua & \\
& & & & U.R.S.S., excepto & $22 / 09 / 86$
\end{tabular}


Resulta revelador que el ámbito subjetivo de aplicación de estos Convenios gire en torno a la figura de la residencia fiscal. El Convenio se aplica a los residentes de uno o de ambos Estados, remitiéndose al concepto que en el Derecho Interno de cada una de las partes firmantes se prevea ${ }^{15}$.

Respecto al ámbito de aplicación objetivo, se aplica a los impuestos contenidos en el Tratado, que normalmente son los Impuestos que gravan la obtención de renta y también el Patrimonio.

En los supuestos en los que existe una doble residencia por parte del sujeto en los Estados firmantes -atendiendo a la normativa interna de cada uno de esos Estados se le atribuye en ambos la condición de residente-, el Convenio establece un mecanismo para determinar donde se localizará la residencia a efectos de la aplicación del Tratado. Resulta necesario que uno de los Estados ceda a parte de su soberanía y deje de considerar al sujeto como residente fiscal, renunciando a someterlo a gravamen por obligación real de contribuir por toda su renta mundial.

Para ello los Convenios suelen contener unos criterios jerárquicos y preferentes que aplican sobre el sujeto, de manera que solo se evalúa el siguiente en caso de que el criterio previo no hubiese sido decisorio.

Una vez determinado el Estado de Residencia a efectos del Tratado, las partes firmantes establecen unas reglas que determinan el Estado competente para someter a tributación la renta.

Por último, señalar que estos Tratados Internacionales, al incorporarse en los Ordenamientos, se superponen jerárquicamente a las normas con rango legal, lo que provocará que ante la presencia de un Tratado aplicable a un hecho que causa un conflicto de doble imposición internacional, debamos obviar los mandatos previstos en la norma tributaria interna que le puedan ser aplicables, y regular el supuesto atendiendo al contenido del Tratado ${ }^{16}$.

Esta razón, unida a que continuamente se incrementa el número de Tratados de este tipo que firman los Estados, hace que debamos fijar la vista en los mismos en relación que a los problemas fiscales que el teletrabajo presenta.

15. Solamente en casos muy concretos se utiliza el término nacional, como un criterio residual y casi en desuso de determinación del Estado que gravaria la renta en supuestos de doble residencia, o en el artículo relativo a la no discriminación.

16. Tal y como se infiere del art.96.1 de nuestro texto constitucional, una vez publicados oficialmente en España, formarán parte del Ordenamiento Interno y se situaran en una posición jerarquicamente superior a las normas con rango legal, ya que solo podrán ser suspendidos o modificados en la forma prevista en los propios Tratados o de acuerdo con las normas generales del Derecho Internacional. 
La Residencla fiscal de la Persona física En El Sistema Tributario Español

Hemos anticipado que nuestro Ordenamiento grava la renta global obtenida por parte de las personas físicas residentes en el IRPF, o solo la renta originada en territorio español cuando es un no residente en el IRNR. Esta aseveración resulta válida siempre y cuando no sea aplicable al hecho y al perceptor de la renta un Convenio para evitar la doble imposición internacional, en cuyo caso será este último el que determinará que jurisdicción someterá la renta a tributación. Pero, tanto para determinar el ámbito subjetivo de un Convenio, como las normas reguladoras de estos tributos, el concepto de residencia fiscal se convierte en el eje nuclear.

Determinar si un sujeto es residente fiscal se convierte en la cuestión crucial para todos aquellos sujetos que perciban rentas, ya que del resultado de este test se derivaba el régimen de tributación aplicable.

\section{La residencia fiscal de la persona física seguin el art.9 LIRPF}

Por tanto, como punto de partida, debemos comenzar exponiendo cuando considera nuestro Ordenamiento residente a una persona física. Para ello, nos debemos remitir al contenido del art.9 LIRPF $^{17}$, que establece dos criterios irrevocables, un tercero presunto y unas normas anti-paraísos fiscales.

$1^{\circ}$ Criterio de permanencia en el territorio español durante mas de ciento ochenta $\mathrm{y}$ tres días.

$2^{\circ}$ La localización en territorio español del núcleo principal o centro de intereses económicos, de forma directa o indirecta.

$3^{\circ}$ Presunción iuris tantum de Vinculación familiar al territorio.

$4^{\circ}$ Normas anti-paraísos fiscales

Los dos primeros criterios, así como una de las dos normas anti-paraísos que contiene el precepto son irrevocables, de manera que cuando concurra alguno de ellos se le imputará al sujeto la condición de residente en España, con independencia de que pueda demostrar que también resulta residente en otra jurisdicción.

\section{a) Permanencia Temporal}

Respecto al criterio de la permanencia temporal, debemos señalar que la prueba material y definitiva de permanencia en el territorio nacional, efectuada en términos horarios y habida cuenta de la libre circulación de personas, resulta poćo menos

17. Los art.5 y 6 LIRNR definen como contribuyente del tributo a las personas fisicas o entidades quie perciban rentas en territorio español y que tengan la condición de no residente, entendiendo por residententè a aquellos delimitados como tales en la normativa del IRPF (personas físicas) y en la normativa del IS. 
que imposible ${ }^{18}$. Este problema de cómputo es resuelto mediante la incorporación de una presunción que considera incluidas las ausencias esporádicas del territorio español a efectos de la cuantificación del periodo de permanencia. salvo que el contribuyente acredite su residencia fiscal en otro país.

$\mathrm{Ni}$ la ley ni su desarrollo reglamentario aclaran que se entiende por ausencias esporádicas. No se fija un límite de tiempo que distinga el carácter de la ausencia como esporádico o definitivo. Una interpretación rígida del precepto, que intenta ensanchar al máximo la consideración de residente, se refleja en el pronunciamiento de la DGT en su consulta 32000 , evacuada el 23 de Febrero de 2000, en el que no asocia la ausencia temporal con un limite de tiempo. Esto nos puede llevar a situaciones radicales y ciertamente atípicas como que una persona que viene a España el 1 de Enero y se marcha el mismo día. y regresa el 31 de Diciembre del mismo periodo impositivo y para marcharse ese mismo día, pueda considerarse, según tenor literal del art.9 LIRPF como residente en territorio español, al computar el resto del año que no permanece en territorio como ausencia esporádica, si bien es cierto que el artículo permite que esta consideración será eliminada cuando el sujeto presente acreditación de su residencia fiscal en otro Estado.

Respecto a esta acreditación, la norma tampoco se refiere a los requisitos que debe cumplir la que provenga del extranjero, aunque la doctrina reiterada de la DGT ha señalado que debe expresar que la persona tiene su residencia fiscal en el Estado que lo expide, debe estar sujeto a imposición en el mismo por su renta mundial y debe ser expedido por la Autoridad fiscal competente. En el caso que exista un Convenio para evitar la doble imposición se adjuntará un certificado de residencia fiscal expedido por la Autoridad fiscal correspondiente, en el que deberá constar expresamente que el contribuyente es residente en el sentido del Convenio ${ }^{19}$.

b) Núcleo principal o centro de intereses económicos

Este criterio tiene su origen en el centro de intereses vitales establecido en el art.4.2 del Modelo Convenio OCDE.

De nuevo nos encontramos ante un concepto jurídico indeterminado, que hecha en falta un desarrollo reglamentario del precepto debido a la inconcreción del mismo. Nos asalta la duda de cómo determinar el núcleo principal o centro de intereses econónicos del contribuyente. De forma inmediata podemos plantear tres variables que podrían ser tomadas como indicativas del mismo: El lugar donde se obtiene la mayor parte de renta, al lugar donde se encuentra ubicado la mayor parte de su patrimonio o el lugar desde donde se gestiona o se administra $o$, incluso, una mezcla de todos ellos.

18. CARMONA FERNÁNDEZ, Néstor, (2001) "La fiscalidad de los no residentes en España: Elementos subjetivos" Dir. CORDÓN EZQUERRO, Teodoro, Manual de fiscalidad..., op.cit.

19. Entre otras, las Resoluciones de la DGT de 30 de Diciembre de 1992, 25 cle Mayo de 1998 y de 25 de Febrero de 2002. 
Tenemos que la mayor parte de la doctrina ${ }^{20}$ se inclina por considerar como criterio principal el lugar de procedencia de las rentas, que se identificaría con el lugar donde se encuentra el establecimiento del pagador del rendimiento. Las razones que se han argumentado son básicamente dos:

1) El hecho de que nos encontremos ante un impuesto que grave la obtención de renta debe hacer que este sea el criterio definitorio, a falta de aclaración normativa o jurisprudencial.

2) Además, el art.59. $2^{\circ}$ LIRPF establece como punto de conexión subsidiario para determinar la residencia habitual en el territorio de una Comunidad Autónoma, el lugar donde el contribuyente tenga su principal centro de intereses, entendiendo como tal el territorio donde obtengan la mayor parte de la base imponible del IRPF, que el caso de los rendimientos del trabajo personal corresponderá con el lugar donde radique el centro de trabajo respectivo.

Otra cuestión controvertida, y que se deriva de la manifestada inconcreción del precepto, radica en si debe compararse el núcleo principal o centro de intereses económicos frente a cada Estado de forma individualizada o erga. omnes, de forma conjunta.

Pese a todo, la cuestión no resulta pacífica, ya que el concepto empleado por el art.9.1.b) LIRPF parece mas apropiada para sujetos que desarrollan actividades empresariales o profesionales ${ }^{21}$ que para personas físicas cuyo rendimientós provienen de una relación laboral dependiente. Resultaría recomendable que se desarrollase el precepto y se aclarase el criterio o criterios relevante.

c) Vinculación familiar

$\mathrm{El}$ art. 9.1.LIRPF presume la residencia en territorio español de la persona física, salvo prueba en contrario, cuando de acuerdo a los criterios anteriores residan en territorio español el cónyuge no separado legalmente y los hijos menores de edad que dependan de aquél.

Respecto a los medios de prueba que se pueden emplear para vencer esta presunción, entendemos que la acreditación de residencia fiscal en otro Estado mediante certificado.

20. Entre ella, citamos a título de ejemplo a GOMEZ CALLEJA, Isabel, "La residencia fiscal en las: nuevas leyes del IRPF e IRNR. Posibles problemas de constitucionalidad" Gaceta Fiscal, n $195 / 2001$; CARMONA FERNÁNDEZ, Néstor, "La fiscalidad de ..." op.cit;

21. En este sentido, la respuesta de la DGT, de 11 de Febrero de 2002, a la Consulta 221-02, señala que en el caso de varios socios que tienen su vivienda habitual en Francia y son propietarios de un negocio en España, que explotan directamente, serán considerados como residentes en territorio: español po considerar que es en éste donde se situa el núcleo principal o la base de sus actividades: o intereses económicos (a expensas de lo dispuesto en aplicación del Convenio Hispano-Francés para: elimar la doble imposición). 
por la Administración tributaria correspondiente solo será suficiente cuando no se trate de un territorio calificado reglamentariamente como Paraíso fiscal. En caso contrario, se tendría que probar la no residencia anadiendo otras pruebas.

\section{d) Normas anti-paraíso fiscal}

Los territorios calificados como paraísos fiscales ${ }^{22}$ suponen una amenaza para la recaudación tributaria de los Estados que se dotan de un sistema fiscal desarrollado. La atracción de capital o la fuga ficticia de residentes para acogerse a un régimen tributario de baja o nula intensidad tributaria muestran algunos de los retos perentorios a los que el resto de Estados deben hacer frente.

Para luchar contra esta amenaza, las principales instituciones supranacionales han recomendado adoptar una posición beligerante frente a este fenómeno y, en esta línea, e inspirada en el régimen previsto en algunos países de Europa (países escandinavos, Dinamarca, Holanda y Alemania) y en EE.UU., la vigente ley 40/1998, de 9 Diciembre, sobre el IRPF ha introducido un mandato. Así, el art.9.3 LIRPF, dirigido a personas físicas de nacionalidad espanola que pretendan trasladar su residencia a un paraíso fiscal, alarga la condición de resiclente fiscal en nuestro territorio al periodo impositivo en el que se materialice el cambio y a los cuatro sucesivos.

El legislador establece una presunción iuris et de iure, presumiendo que todo traslado de un nacional a un paraíso fiscal se produce, en cualquier caso, por motivos fiscales y, para evitar este cambio ficticio de residencia, establece una prorroga legal de la condición de residente.

Debemos comentar que el precepto resulta, cuanto menos, controvertido al hilo de la Jurisprudencia reiterada del TJCE en relación al Principio de No Discriminación, Principio altamente protegido por la Corte europea, y que tiene como único propósito evitar dentro de un Estado la existencia de diferentes sistemas que dependan de la nacionalidad ${ }^{23}$.

GÓMEZ CALLEJA cuestiona la constitucionalidad del precepto y utiliza como argumento la vulneración del Principio Constitucional de Igualdad recogido en el art.14 de CE, al hilo de la doctrina de nuestro máximo interprete, manifestada

22. En nuestra normativa interna, el Real Decreto 1080/1991, de 5 de Julio, establece una enumeración de los mismos.

23. Esta sería una variante inversa de discriminación, en la medida en que discrimina de forma negativa a los ciudadanos nacionales en relación a los no residentes, cuando lo habitual suele ser la discriminación de signo contrario. Algunas sentencias que se han pronunciado sobre este tema son: Caso Werner (C112-91) y Asscher (C107/94). Para mayor abundamiento, consúltese a GARCÍA PRATS. (1998), Imposición directa, no discriminación y Derecbo Comunitario, Tecnos, Madrid. 
claramente en la STC ñ $76 / 1990$, de 26 de Abril, sobre el alcance de este principio ${ }^{2+}$

Como bien señala GÓMEZ CALLEJA ${ }^{25}$, una manera de evitar la aplicación del preceptø: en la práctica, será efectuando un traslado indirecto, a fin de que el cambio de residencia! hacia un paraíso fiscal se realice tras haber permanecido durante un año en otro país.

Otra norma agresiva contra el cambio de residencia a estos territorios la encontramos: en el requisito adicional que establece el art.9.1 LIRPF para acabar con la presunción del cómputo de las ausencias esporádicas en el criterio temporal de residencia. No bastará con: que el contribuyente presente un certificado fiscal acreditativo de la residencia en ese otro: territorio, emitido por el órgano tributario competente al efecto, sino que además la Administración tributaria se reserva el derecho de poder exigirle que pruebe la permanencia en el mismo durante ciento ochenta y tres días en el año natural. Pero inmediatamente, la cuestión se centra en determinar como probar esa permanencia en ese territorio, lo cual: nos hace plantearnos varios aspectos:

¿Resultará válido el método de cómputo para determinar el periodo de permanencia previsto en el art.9.1 LIRPF y que computa las ausencias esporádicas? La ley no se pronuncia al respecto, y a falta de otro criterio, han surgido voces en la doctrina que consideran aplicable el método de cómputo general ${ }^{26}$. Sin embargo, no parece que esa: sea la finalidad perseguida por el legislador, sino mas bien todo lo contrario, obstaculizat: los posibles cambio de residencia ficticios a estas zonas. Por ello, resulta necesario una: nueva redacción o un desarrollo reglamentario del precepto, que aclare expresamente. esta cuestión.

¿Si la certificación fiscal emitida por el otro Estado resulta insuficiente, que medios de prueba se podrían usar?. La DGT, en consulta de 22 de Junio de 1999, ha señalado que "La apreciación de pruebas aportadas habrá de ser efectuada en cada supuesto concreto por la Administración tributaria, sin que pueda enunciarse de modo general y teórico los medios de prueba que sirven para demostrar la permanencia efectiva, que procederá analizari

24. GÓMEZ CALLEJA, Isabel, (2001) "La residencia fiscal...", op.cit.considera que el art.9.3 LIRPF también puede ser considerado inconstitucional. Argumenta su posición en el hecho de que "... no se admita prueba en contrario, pues al anularse radicalmente la posibilidad de prueba, el contribuyente queda en flagrante indefensión (...) En el artículo 9.3 LIRPF, el principio de contradicción, base de todo el art.24 CE, queda' absolutamente desvirtuado, al no ser viable ni la mas mínima actividad probatoria. La cuestión sobre la que venimos reflexionando es la proporcionalidad del precepto, atendiendo a los fines perseguidos por el legislador: Tras el estudio realizado, cabe concluir que dicha proporcionalidad se ve vulnerada, al existir orras posibilidades, como el mecanismo de inversión de la carga de la prueba, mediante el uso de una presnciôn iuris tantum".

25. GOMEZ CALLEJA, Isabel, (2001) "La residencia fiscal...", op.cit.

26. Esta posición parece inferirse a AGULLó AGüERO, Antonia, (1999) "Comentarios a los artículos 8 a 11 de la Ley de IRPF", Coord. OROL MORATAL, Los nuevos Impuestos sobre la Renta de las personas fusicas $y$. sobre la renta de los no residentes. McGraw Hill, Madrid. 
caso por caso cada supuesto". Como señala GÓMEZ CALLEJA ${ }^{27}$, parece que la solución habrá de ser casuística, lo cual no redunda en una mayor seguridad jurídica del contribuyente.

\section{Modelo de Convenio de la OCDE}

Las tres funciones fundamentales del concepto residente fiscal en el Modelo de Convenio de la OCDE son:

- Criterio de determinación del ámbito subjetivo del Convenio

- Para resolver los casos en que la doble imposición se produzca como consecuencia de la doble residencia.

- Para resolver los casos en que la doble imposición resulte del gravamen en el Estado de residencia y en el Estado de la fuente o situación.

Como ya hemos señalado, el art. 4.1 del Modelo $^{24}$ se remite a la legislación de los Estados contratantes a los efectos de la determinación de la residencia, por lo que en nuestro Ordenamiento, y en el caso de personas físicas, nos remitimos a los criterios, que acabamos de exponer, contenidos art.9 LIRPF.

Debemos de destacar que este artículo establece como requisito que el concepto de residencia previsto por cada Estado vincule al sujeto por obligación personal, sometiendo a gravamen su renta mundial.

En los supuestos de doble residencia, los criterios jerárquicos y preferentes que prevé el art.4.2 del Modelo de Convenio serian, en este orden ${ }^{21}$

27. GOMEZ CALLEJA, Isabel, (2001) "La residencia fiscal...", op.cit.

28. El Modelo de Convenio de la OCDE establece en su articulo 4.1.: "1. A los efectos de este Convenio, la expresión -residente de un Estado contratante. significa toda persona que, en virtud de la legislación de ese Estado, esté sujeta a imposición en el mismo por razón de su domicilio, residencia, sede de dirección o cualquier otro criterio de naturaleza análoga, incluyendo también a ese Estado y a sus subdivisiones políticas o entidades locales. Esta expresión no incluye, sin embargo, a las personas que estên sujetas a imposición en ese Estado exclusivamente por la renta que obtengan de fuentes siruadas en el citado Estado, o por el patrimonio situado en el mismo.

29. El art. 4.2. del Modelo de Convenio de la OCDE señala que: "Cuando en virtud de las disposiciones del apartado 1 una persona fisica sea residente de ambos Estados contratantes, su situación se resolverá de la siguiente manera:

a) dicha persona será considerada residente solamente del Estado donde tenga una vivienda permanente a su disposición; si tuviera una vivienda permanente a su disposición en ambos Estados, se considerará residente del Estado con el que mantenga relaciones personales y económicas más estrechas (centro de intereses. vitales);

b) si no pudiera determinarse el Estado en el que dicha persona tiene el centro de sus intereses vitales, o si no tuviera una vivienda permanente a su disposición en ninguno de los Estados, se considerará residente solamente del Estado donde viva habitualmente.

c) si viviera habitualmente en ambos Estados, o no lo hiciera en ninguno de ellos, se considerará residente solamente del Estado del que sea nacional;

d) si fuera nacional de ambos Estados, o no lo fuera de ninguno de ellos, las autoridades competentes de los Estados contratantes resolverán el caso de común acuerdom. 
$1^{\circ}$ La vivienda permanente. No requiere que la persona sea propietaria del inmueble, bastará con que lo posea con carácter permanente. Como señala los comentarios del Tratado a este artículo, que la persona lo haya amueblado y reservado para su uso con intención de permanencia.

$2^{\circ}$ Centro de intereses vitales. Atiende al lugar donde se encuentran sus relaciones personales, familiares y sociales de la persona, donde se encuentra su negocio o el lugar desde donde gestiona su patrimonio.

$3^{\circ}$ Presencia Habitual. Se refiere a estancias de cualquier tipo, por cualquier razón y en cualquier lugar: viviendas, hoteles, etc.

$4^{\circ}$ Nacionalidad

Si ninguno de estos criterios fuese suficiente para determinar la residencia en un Estado en perjuicio del otro, la cuestión se resolverá mediante la aplicación del procedimiento amistoso contenido en el art.25 del Convenio, por el que las partes, de mutuo acuerdo, determinaran la jurisdicción a quien se atribuirá la residenciáa fiscal en exclusiva.

\section{Criterios De Sujeción De las Rentas Procedentes Del Teletrabajo}

\section{Modelo de Convenio de la OCDE}

Cuando se presente un supuesto de doble imposición internacional, al quedar gravada una misma renta por el Estado de residencia y de la fuente, o bien por imputarle al sujeto una doble residencia, una vez determinada la residencia fiscal exclusiva según Convenio, resulta fundamental determinar quien resultará beneficiado por el reparto de potestades tributarias. Pese a que siempre tengamos que atender a las particularidades que contiene cada Tratado, inferimos del art.15 del Modelo de Convenio de la OCDE, que en el caso de servicios personales. dependientes-sueldos, salarios y otras remuneraciones similares-, se someterán a imposición en el Estado donde el empleo se ejerza efectivamente, salvo que concurran los siguientes requisitos:

a) Que la persona que lo realice no permanezca en dicho Estado durante mas de 183 días durante un periodo de 12 meses.

b) Que la renta no se pague por un residente o un establecimiento situado en ese Estado.

De no concurrir estos requisitos, este precepto otorga la potestad tributaria al Estado de la fuente cuando el perceptor de las rentas se desplaza a ese Estado para realizar el trabajo, "donde el empleo se ejerza efectivamente".

Sin embargo, en aquellas actividades donde la prestación del servicio laboral se realiza a través del teletrabajo, el Principio de la fuente puede resultar sustituido por 
el de la residencia ${ }^{30}$, al no ser necesario que el trabajador se desplace al país donde se utilizará el servicio y/o desde donde se realiza el pago, ya que el servicios se prestará desde donde resida el trabajador siendo éste el lugar "donde el empleo se ejerce efectivamente".

\section{$I R N R$}

Otra cuestión controverticla se plantea en los supuestos en los que no resulta aplicable Convenio, y en los que concurre, por un lado, que el teletrabajador no cumple ninguno de los criterios previstos en el art.9 LIRPF para atribuirle la condición de residente $y$, por otro, que presta sus servicios a una empresa establecida o residente en territorio nacional.

Según la LIRNR, que como ya hemos señalado establece en su art. 5 y 6 como contribuyentes a los no residentes, dispone sus art.11.1. 12.1.c), 12.2 y 12.3.d), que el hecho imponible del impuesto lo constituye la obtención de rentas, dinerarias o en especie, en territorio español, considerando como tales, entre otras, los rendimientos del trabajo cuando deriven, directa o indirectamente, de éste. Como norma general y para todas las rentas, prevé que se entenderán obtenidos en territorio espanol los rendimientos satisfechos por establecimientos permanentes o residentes en éste territorio.

Sin embargo, esta regla general del pago desde territorio espanool, tras analizar detenidamente el punto 3 del art.12, comprobamos como resulta residual, limitándose a los rendimientos del capital mobiliario. La mayor parte del resto de los rendimientos, entre ellos las percepciones provenientes del trabajo personal recogidas en el art.16.1 LIRPF $^{31}$, quedarán normalmente ajenos a este criterio. Así, estos rendimientos del trabajo personal, no quedaran sujetos al IRNR cuando se cumplan dos circunstancias de forma simultánea:

- Que el trabajo se preste íntegramente en el extranjero

- Que los rendimientos se encuentren sujetos a un impuesto de naturaleza personal en el extranjero.

Ante la falta, una vez más, de desarrollo de los preceptos, nos planteamos si el segundo requisito solo se refiere a impuesto de naturaleza personal para establecer un gravamen que le obligue a tributar por su renta mundial, y si sería aplicable el límite mínimo previsto en el art.5.1.2 $2^{\circ}$ RIRPF para aplicar la exención a los

30 DE JUAN LEDESMA. Álvaro, (2000) "Fiscalidad del Comercio Electrónico: mito o realidad", Revista de Estudios Financieros, $n^{\circ} 204$.

31 Sueldos y salarios; prestaciones por desempleo; remuneraciones en concepto de gasto de representación; dietas y asignaciones para gastos de viaje no exentos; $y$ las contribuciones de promotores y empresarios a planes de pensiones cuando las mismas sean imputadas a aquellas personas a quienes se vinculen las prestaciones. 
rendimientos percibidos por trabajos realizados en el extranjero, prevista en el art. 7 p LIRPF). Según éste precepto reglamentario, se requiere que los rendimientos del trabajo hubiesen tributado en el extranjero por un impuesto de naturaleza idéntica o similar al IRPF, considerando que concurre esta circunstancia cuando el contribuyente en el IRPF hubiese ingresado, en este concepto, al menos el $50 \%$ de lo que le correspondería pagar en España aplicando el tipo medio efectivo del IRPF sobre esos rendimientos.

Consideramos que por la estrecha relación entre ambos impuestos y entre ambos conceptos (impuesto de naturaleza personal frente a impuesto de naturaleza idéntica o análoga), podría ser utilizado este criterio para delimitar el tipo de gravamen mínimo exigible que debería ser aplicable al gravamen extranjero requerido en el art.12.3.d) LIRNR. Sin embargo, consideramos que lo mas oportuno sería un desarrollo reglamentario del precepto, al estilo del art.5 RIRPF, que solventase esta cuestión.

A efectos del teletrabajo, el primero de los requisitos se conseguirá trasladándose al extranjero y el segundo dependería de la Jurisdicción en la que residiera el trabajador. Pendientes de si el sujeto pudiera ser considerado como residente en territorio nacional por la aplicación del criterio del centro de intereses económicos cuando percibiera de un pagador residente o establecido en nuestro territorio, y a falta de una solución definitiva al respecto, si la respuesta fuese negativa, nos llevaría a considerar que un trabajador residente podría planificar su tributación trasladando su residencia a otro Estado, pudiéndose ahorrar, hasta un $50 \%$ de la cuot, de ser aplicable una interpretación paralela al contenido del art. 5.1.2 $2^{\circ}$ LIRPF.

Sin embargo, la normativa vigente no favorece los intereses del sujeto al trasladarse a un territorio calificado como paraíso fiscal, ya que, por un lado, el sujeto vería prorrogada su condición de residente durante cinco años, como consecuencia de la disposición anti-paraísos fiscales prevista en el art.9.3 LIRPF, y por otro, tampoco sería posible aplicar la exclusión prevista en el art.12.3.d) LIRNR de la regla general del pago desde un establecimiento localizado en territorio nacional, al carecer aquel de un impuesto de naturaleza personal tal y como lo entendemos.

\section{CONCLUSIONES}

La aparición del teletrabajo internacional puede provocar que aquellos; supuestos que se acojan al Modelo de Convenio de Doble Imposición de la OCDE, obsèrven como los supuestos de tributación en la fuente de los rendimientos procedentes de la prestación de servicios laborales, sean sustituidos para esta nueva modalidad laboral por el criterio de residencia. 
Esta nueva situación descompensa la voluntad inicial de las partes en el momento de la firma del Tratado, a favor del Estado residente, que observa como el desarrollo de las nuevas tecnologías y su aplicación en el campo laboral , provocan un incremento de sus potestades y un mayor sacrificio para el Estado de la fuente, en supuestos de doble imposición internacional que se acogen al Modelo de Convenio de la OCDE.

Se posibilita al teletrabajador la planificación internacional, al utilizar el traslado de su residencia, ya que le puede resultar atractivo cambiarla a algún Estado, con el que se hubiese firmado un Convenio de Doble imposición, que tenga una tributación sobre la renta inferior a la de su Estado de origen.

Pero también le puede resultar ventajosa trasladarla a un Estado, que no tenga la condición de Paraíso Fiscal, y con el que no exista un Convenio firmado para la eliminación de la doble imposición, pese a que el pagador y el uso de ese servicio se encuentren en territorio nacional. En estos casos, sería de aplicación la excepción prevista en el art.12.3.d) LIRNR, cuando en los rendimientos obtenidos queden sujetos a otro impuesto de naturaleza personal en el extranjero, siempre que se cumpliese esta última condición.

Por el contrario, la planificación fiscal basada en un cambio de residencia a un paraíso fiscal quede desencentivada. Debemos manifestar que pese a los problemas, esgrimidos anteriormente, de constitucionalidad y de respeto al Principio defendido por el TJCE de No Discriminación del art.9.3 LIRPF, su establecimiento, previsto inicialmente para evitar los cambios ficticios de residencia hacia paraísos fiscales de deportistas y artistas que realizan gran cantidad de viajes a lo largo del año, resulta de gran utilidad para evitar que esos comportamientos poco deseables se extiendan hasta los teletrabajadores. La prórroga de la residencia fiscal en territorio espanol durante 5 años, junto con la no aplicación de la excepción del art.12.3.d) LIRNR, desincentivará esos comportamientos fraudulentos.

Si los Convenios quieren seguir manteniendo el mismo reparto de potestades tributarias que venían realizando hasta ahora, deviene imprescindible que se modifique el art.15 del Convenio o bien los comentarios al mismo, de manera que para las nuevas modalidades de trabajo dependiente prestadas a distancia, se establezca como criterio de sujeción el lugar donde se encuentre el pagador o donde sea utilizado el servicio. Y en la misma línea, se debería plantear la vuelta al criterio del lugar desde donde se localice el pago para supuestos de rentas de teletrabajo internacional, a efectos de la normativa interna que vincula por obligación real de contribuir al perceptor de la renta. En nuestro Ordenamiento, solicitamos que la excepción prevista en el art.12.3.d) LIRNR no se aplique a estos supuestos. 
BiBLIOGRAFía

AGULLÓ AGÜERO, Antonia, (1999) "Comentarios a los artículos 8 a 11 de la Ley dé IRPF", Coord. OROL MORATAL, Los nuevos Impuestos sobre la Renta de las personasy fisicas y sobre la renta de los no residentes, McGraw Hill, Madrid.

ALMUDÍ CID, José y SERRANO ANTÓN, Fernando, (20001) "La residencia fiscal dé las personas físicas en los Convenios de doble Imposición Internacional y en la normativa interna española", Revista de Estudios Financieros, $\mathrm{n}^{\circ} 221-222$

CARMONA FERNÁNDEZ, Néstor, (2001) "La fiscalidad de los no residentes en España:" Elementos subjetivos" Dir. CORDÓN EZQUERRO, Teodoro, Manual de fiscalidad" Internacional, Instituto de Estudios Fiscales.

DE JUAN LEDESMA, Álvaro, (2000) "Fiscalidad del Comercio Electrónico: mito o realidad", Revista de Estudios Financieros, $n^{\circ} 204$.

DE JUAN LEDESMA, Alvaro, (1995) "La personalización de los establecimientos permanentes", Revista de Estudios Financieros, $n^{\circ} 146$,

FERREIRO LAPATZA, José J., (1996) Curso de Derecho Financiero Español, Marcia Pons, Madrid.

GALTÉS VICENTE, Meritxell, (2001)

"El concepto de Residencia de las Personas Físicas" Revista Economía Social y de la Empresa, $n^{\circ} 37$.

GÓMEZ CALLEJA, Isabel, (2001) "La residencia fiscal en las nuevas leyes del IRPF e IRNR. Posibles problemas de constitucionalidad" Gaceta Fiscal, nº195.

PÉREZ DE AYALA BECERRIL, Miguel, (1997) "La nueva regulación del domicilio fiscal a efectos del impuesto sobre la renta de las personas físicas en las comunidades autónomas", Revista de Estudios Financieros, n 172.

RUBIO GUERRERO, Juan José, (2001)

"Los Principios básicos de la fiscalidad internacional y la doble imposición internacional", Dir. CORDÓN EZQUERRO, Manual de Fiscalidad Internacional, Instituto de Estudios Fiscales.

SAINZ DE BUJANDA, Fernando, (1975)

"Derecho Fiscal Internacional", Hacienda y Derecho I, I.E.P.

SOPENA, (1991) "La eficacia de las leyes tributarias en el espacio", Comentarios a la LGT y líneas para su reforma vol.I, Insituto de Estudios Fiscales, Madrid. 